\title{
Co-creation of Social Innovations and New Professional Institutions: Diffusion of therapeutic patient education (TPE) for diabetes in Austria
}

\author{
Paul Windrum (CHILL, Nottingham University Business School \\ Nottingham, UK) Paul.Windrum@nottingham.ac.uk \\ Doris Schartinger (Austrian institute of Technology \\ Vienna, AT) Doris.Schartinger@ait.ac.at \\ Justin Waring (CHILL, Nottingham University Business School \\ Nottingham, UK) Justin.Waring@nottingham.ac.uk
}

http://dx.doi.org/10.1080/13662716.2017.1295363

\begin{abstract}
Patient-centred education in diabetes is a radical social innovation that alters the social and medical relationship between patients and medics. This paper discusses the ways in which institutional work conducted by national and international professional associations has shaped development and diffusion of this social innovation within the Austrian health system.

The case study contributes to our understanding of social innovation and institutional change in two respects. First, it highlights the need for purposive institutional work in order to disrupt pre-existing institutions and, thereby, ensure the development and diffusion of a social innovation amongst a community of medical practitioners. Second, the case shows the overtly political work, policing, and educating work that professional associations undertook with funding bodies and key policy-makers in order to develop a national programme for diabetes education.
\end{abstract}

Keywords: social innovation, institutional work, diabetes education, hospitals.

Word length (not including tables and references): 9,129. 


\section{INTRODUCTION}

This paper contributes to this special issue by examining the link between institutional change and the development and diffusion of therapeutic patient education (TPE) for Type 2 diabetes in Austria. TPE is a radical social innovation, founded on an alternative patient-practitioner relationship in which the patient, not the medic, is the expert for managing their own condition. The importance of new institutions - involving changes in social practices and social structures - to the development of social innovations has been highlighted by Ruede and Lurtz (2012), and by Reinstaller (2014). Institutions involve deeply embedded and enduring regulative, normative and cognitive elements that both constrain and support the operation of individual organizations (Scott 2008). They are the "the rules of the game in a society, [...] humanly devised constraints that shape human interaction" (North 1990, p.3). In addition to formal laws and constitutions that enforce behaviour, there exist informal social norms that are enforced through expressions of disapproval, ridicule, ostracism or codes of honour (Elster 1989).

There exists an established research literature on the importance of professions for the development of diffusion of new practices in medicine. The institutional work conducted by professionals is important because clinical trial empirical evidence alone may be insufficient to ensure the diffusion new medical practices and treatments (Greenhalgh et al. 2004; Ferlie et al. 2005). Indeed, as our case study shows, this was the case for TPE for Type 2 diabetes in Austria.

In our case study, a number of national professional associations, linked to powerful international associations, undertook the development, coordination and political work needed for TPE for Type 2 diabetes to be funded and delivered in Austrian hospitals and registered practices. The contributions of professional associations - supra-organizations that span members of individual hospitals - have not been addressed in prior research. Rather, the focus has previously been on institutional work conducted within single locations, usually hospital departments.

This case study provides a unique opportunity to examine the type of institutional work required to establish a social innovation within medicine. It shows how a social innovation in chronic healthcare management, previously developed and tested in Germany and Switzerland, enter the Austrian healthcare system. This occurred through an interplay between various national professional associations, university hospitals and key policy organizations. The institutional work which was essential for this social innovation to take diffuse was, to a large extent carried out at the organizational level, though linked by individuals and set against an international context of the St. Vincent Declaration and actions of international organizations such as the WHO, IDF and EASD.

The case study contributes to our understanding of social innovation and institutional change in two areas. First, it highlights the need for purposive disruption of pre-existing institutions in order for social innovations to develop and diffuse. A radical dis-juncture exists in the cognitive base of patient-centred health - the 'conceptual core' comprising TPE and evidence-based medicine (EBM). Second, the case highlights the institutional work conducted by supporting associations with funding bodies and other key policy-makers. This overtly political and 
coordination work is shown to be essential for the development of the national Diabetes Management Programme 'Therapie Aktiv' (DMP).

\section{The social innovation in focus}

Research on social innovations is still a rather new field and a single definition does not yet exist (see the Introduction to this special issue). Rather than comprehensively discussing this here, we highlight certain aspects of prior research that are relevant to our case study.

Social innovations are new responses to pressing social needs, and create new social relationships or collaborations. Social innovations are therefore 'social' in both their ends and their means (BEPA 2010). Richez-Battesti and Vallade (2009) stress that, as well as being a product, production process, or technology (much like innovation in general), social innovations can also be a principle, an idea, a piece of legislation, a social movement, an intervention, or a combination thereof.

The Stanford Social Innovation Review (Phills, Deiglmeier, and Miller 2008) highlights the issue of market failure with respect to social innovations. Market failure can arise when the social returns of investment are greater than the private returns, or else the commodity/service is a 'public good'. The latter has two characteristics: it is non-rivalrous (when a good/service is consumed this does not reduce the amount available for others), and non-excludable (it is not possible to provide that good/service without it being possible for others to enjoy). Where there is a market failure, the development and delivery of social innovations may depend on public sector or third sector (not-for-profit) providers, or even self-provision by local communities.

Intentionality and social impact is another aspect highlighted in the social innovation literature. For example, Chiappero-Martinetti and Von Jacobi (2015) position social innovation as a solution to some of the causes of and problems arising out of marginalisation, where marginalisation is a social process through which personal traits are transformed into potential factors of disadvantage. Mendell and Neamtan (2010) view social innovation in terms of governance, participation and empowerment. Empowerment may occur through the creation of new roles and relationships (e.g. between the citizen and the state), or the development of assets and capabilities, or the more efficient and environmentally sustainable use of existing assets and resources (Science Communication Unit, 2014; Chiappero-Martinetti and Von Jacobi, 2015). This may require changes in the design, organization and delivery of these services/products, and relationships between organizations involved in the supply and regulation of these services/products (Pol and Ville, 2009; Ruíz Viñals, 2013; Hochgerner, 2013; Howaldt and Jacobsen, 2010; Windrum et al. 2016b).

Finally, Windrum et al. (2016b) observe that attitudes towards imitation can differ between social innovators and their private sector service counterparts. Whereas private sector innovators normally discourage innovation, e.g. through patents and other forms of intellectual property protection, in order to gain a temporary monopoly rent from successful innovation activities, social innovators often encourage imitation. When solutions for a problem are scarce 
and competition therefore weak, once a solution is taking shape the goal is to invite others to follow the same pathway rather than exclude them.

The development and diffusion of TPE for Type 2 diabetes is a radical social innovation, both in process and in outcome. TPE seeks to address chronic health problems by placing the patient at the heart of the process, rather than the medical practitioner. The rationale is that the patient is the 'expert' on their daily management of their chronic condition, and on how to improve their lifestyle (including diet and physical activity) to assist the better management of their condition over time. The TPE model for Type 2 diabetes recognises that diabetes is largely a 'self-managed' condition with day-to-day management in the hands of the patient, who must make long-term healthy lifestyle changes involving diet, exercise, and medication. Selfmanagement plans should be developed and maintained through collaboration between patients - who bring to the table their concerns, priorities, knowledge and resources - and the clinical expertise of healthcare professionals. The practitioner therefore plays a facilitating and support role in this model. This contrasts sharply with the traditional compliance model. In that model, the patient is a passive recipient of standardized information, provided to all patients. The healthcare professional is an expert who prescribes and defines good practice in diet, exercise and lifestyle choices. Then, the passive patient is expected to adhere to the plans and prescriptions devised by the healthcare expert.

TPE also involves societal change, as this alternative medical relationship depends upon the empowerment of citizens (patients). The framing of the TPE programme for those newly diagnosed with Type 2 diabetes not only establishes a new patient-practitioner relationship, it is also the start of a process of patient empowerment. This aim of patient empowerment is very much in line with Mendell and Neamtan's (2010) discussion of social innovation. The stakeholders involved in this social innovation are seeking to address a societal challenge based on new ways of empowering citizens (patients), thereby transforming the traditional roles and responsibilities of medical practitioners and patients.

The delivery of TPE requires the (re)training and education of doctors and nurses in new approaches that support patient-centred health. Patient-centred health is more demanding of practitioners, requiring them to understand and deal with the lifestyles and socio-economic conditions of patients, and is more time-consuming. These skills are not developed in the traditional programmes of medical schools.

Finally, our case study shows the ways in which advocates of TPE imitate and learn from each others' experiences, within Austria and from other countries, and how this 'cognitive coordination' was organized through new associations for diabetes doctors and nurses in Austria. The diffusion of TPE information spread freely from the early pioneers to others who were willing to apply the insights. These associations established conferences and other events at which international pioneers at university hospitals in Germany and Switzerland spoke of their research and learning in practice. This inspired the Austrian patient-centred model. In turn, Austrian diabetologists connected with British specialists who later conceptualised and implemented the DAFNE programme. 


\section{INSTITUTIONAL CHANGE AND INNOVATION}

Coriat and Weinstein (2002) raise the question of 'what are the relevant organizations/ institutional components to consider when seeking to understand innovation dynamics?' In their analysis of innovation and institutional change in commercial markets, they highlight the role(s) that public organizations, universities and other non-commercial organizations play, spanning firm boundaries in order to produce, manage, and diffuse of scientific and technical knowledge (also see Edquist and Johnson 1997 on this point).

There exists, across the studies of healthcare innovation, a number of frameworks and models explicitly concerned with accounting for the way innovations become institutionalised within healthcare delivery (e.g. Damschroder et al. 2009; Greenhalgh et al. 2004; Kitson et al. 2008). For example, Normalisation Process Theory (NPT) is a 'middle-range' framework and set of inter-linked concepts for analysing the adoption and embedding of healthcare innovations (May and Finch, 2009; Murray et al. 2010). Drawing on theories and concepts within sociology, organizational science, and science and technology studies, NPT comprises four main constructs: coherence, cognitive participation, collective action and reflective monitoring.

'Coherence' draws on the extensive body of research on 'sense-making' (e.g. Weick 1985) and attends to the way actors perceive and give meaning to both the problems they face in their work and the potential contribution for an innovation. 'Cognitive participation' draws on research related, for example, to communities of practice (Lave and Wenger 1991), and examines the way social practice form around particular innovations. 'Collection action' draws on research related, for example, social movements (Fligstein and McAdam 2012), to examine the way groups mobilise and act in coordination to implement an innovation. 'Reflective monitoring' attends to the work involved in appraising change processes to inform incremental adjustments.

NPT provides a set of concepts and tools for examining the institutionalisation and embedding of innovations. Significantly, however, it does not explicitly consider the necessary deinstitutionalisation of prevailing institutional configurations, when implementing change.

Hargrave and van de Ven (2009) observe a fundamental processual contradiction that all institutional actors must embrace is the stability/change contradiction. Evolution within a field can be pushed in new and unexpected directions by changes in external, pan-institutional factors such as technology, demographics, and new political and social challenges. All actors must effectively address these external challenges, while simultaneously creating stability within a field (e.g. a medical field). Where a set of actors respond by seeking to develop a new institution, creation and disruption goals are synonymous within a particular set of institutional work activities. Institutional activities that seek to develop and diffuse a new institution simultaneously involve purposive disruption.

A useful literature which tackles the issues of de-institutionalization and institutional change is that of institutional work. Institutional work is the "purposive action of organizations and individuals aimed at creating, maintaining and disrupting institutions" (Lawrence and Suddaby 2006, p.215). Research in this area focuses on how institutional work occurs, who does institutional work, and what constitutes institutional work. The issue of how institutional work 
occurs is considered by the Lawrence and Suddaby (2006) taxonomy which, drawing upon prior studies, identifies different types of work activities involved in creating, maintaining, and disrupting institutions.

In their recent review of the institutional work literature, Lawrence et al. (2013) highlight the lack of prior research on the destruction of institutions, or the ways in which established institutions are challenged and disrupted as part and parcel of institutional change within a field. Notable exceptions are provided by Oliver's (1992) discussion of de-institutionalisation as a process, and Maguire and Hardy's (2009) study of the de-institutionalization of DDT which shows the importance of practice work and boundary work to field-level change.

Our research addresses this research gap by examining the link between different types of disruption and creation work undertaken by medical professionals within Austria who sought to diffuse TPE within diabetes medicine. Rather than being distinct, some of the institutional work placed in the categories of 'creating institutions' and 'disrupting institutions' may well be linked, suggesting that actors are engaged in certain work activities that create a new institution while simultaneously disrupting a pre-existing institution. This institutional work is likely to bring this actor, or group of actors, into direct conflict with those wishing to maintain the established institution.

The issue of who engages in institutional work has highlighted, on the one hand, actors at the top of organizations linking the creation of institutions with institutional entrepreneurship, and, on the other hand, professionals. In medicine, occupational professionalism has historically been the dominant alternative to both the market and to public bureaucracy for the organization of work and the delivery of health services (McClelland, 1990; Evetts, 2006). Occupational professionalism places emphasis on autonomy and the self-regulation of work by medical practitioners, with health professionals best placed to act in the best interests of their patients (clients). A core component of occupation professionalism is client trust. The professional ethic of nil nocere ('do no harm') and patient confidentiality both date back to the Hippocratic Oath in the 5th century BC, and have their modern embodiment in the Declaration of Geneva.

In addition to client trust, core components of occupational professionalism in medicine are specialist knowledge and skills, founded on the theoretical foundation of a particular medical sub-field, moral commitment, discretionary decision-making, and self-regulation. Governance is through collegial relationships and working arrangements. Professional values emphasise a shared identity based on competencies (produced by education, training and apprenticeship socialisation) and legal responsibility (sometimes guaranteed by licensing). Professional relations are characterised as cooperative and mutually supportive, and relations of trust characterise practitioner-client and practitioner-employer interactions. This is a demonstrable alternative to managerial hierarchy for the organization of work and workers, with different work relationships, to attain a particular normative outcome.

Much of the scholarship on professionalism has addressed the challenge(s) to medical professionalism posed by New Public Management (Hood, 1991) and its successors. Managerial/organizational professionalism is an increasingly prevalent (neo-liberal) managerialist version of professionalism which serves the interests of the organization and its 
management rather than professional groups (Evetts, 2006). Institutional change has been seen as either tied to a challenge to the autonomy and power of doctors (e.g. Light, 1995; McKinlay and Stoeckle, 1988; Scott et al. 2000) or, alternatively, as being driven by doctors are as actively resisting, adapting to or capturing managerialist reforms on order to advance their own interests (e.g. Freidson 1985; Waring and Currie 2009).

Our case study differs as the conflict is one between medical professionals within a particular medical field - diabetology - rather than between not between managerial and medical professionals. Here institutional disruption and change is shaped by the rivalry between those diabetologists championing a social innovation in patient education and treatment, and those who maintain the established institution of practitioner-driven health within diabetology.

The case study shows the important role played by professional associations within this fieldlevel conflict. Associations are a visible organizational form that can support stability or change within medicine. Professional associations conduct the institutional work needed to develop and maintain what Coriat and Weinstein (2002) call 'cognitive coordination' and 'political coordination'. Cognitive coordination concerns the collective capacity of a community of practitioners to produce and innovate over time. This requires the effective management in the dissemination of information and knowledge. Political coordination concerns the establishing and maintaining compatibility amongst the interests of individual members, and the management of (potential) conflicts through combinations of incentives and authority.

\section{METHODOLOGY}

\subsection{Data Collection}

Rendering institutional work visible requires rich, detailed case studies (Lawrence et al. 2009; Currie et al. 2012). We have gathered data from 1995 to the present time, using four types of sources on the diffusion of patient-centred health services for Type 1 and Type 2 diabetes patients in Austria (table 2). The primary and largest data source is drawn from documentary and archival data from various related sources dating from the mid-1980s to the present time. This includes (a) extensive documentary data and policy background data that has been collected on the 'Disease management programme' programme for diabetes education, (b) archive data from Association of Diabetes Specialists, and the Association of Diabetes Educators, (c) archive materials from the Austrian Diabetes Society (ÖDG 2009, 2012), and international diabetes organizations such as the International Diabetes Federation (IDF 2009, 2011) and the European Association for the Study of Diabetes (EASD 2013), and from diabetes patient organizations. Documentary data was initially selected to gather a broad and general understanding of the field of diabetes care within Austria, changing forms of evidence and significant advances in service provision, especially the introduction of patient-led services. As the study progressed, documentary analysis involved more purposive selection of policies, and documents that demonstrated the particular strategies and activities of groups and actors in bringing about change. This secondary data was archived electronically by source and type with cross-referencing by theme, and comprised a strong historical reference point on which to build the analysis of institutional work. 
In addition, to documentary data collection, the study also involved semi-structured interviews and non-participant observations with doctors promoting TPE, who are also part of the Association of Diabetes Specialists, leading members of Association of Diabetes Educators, with senior members in the Physicians' Chamber and the Social Healthcare Insurance Fund, and with a leading cardiologist (to have an outside view).

Purposeful sampling (Kumar et al. 1993), was applied to all key informants with insight into the organization and diffusion of Type 1 and Type 2 patient services in Austrian hospitals and/or unique access to knowledge of the history, strategies, and actions involved. In the first instance, participants were identified through the aforementioned documentary analysis. Specifically, through a scientometric study of international citations of random-controlled trials of patient centred education programmes for diabetes patients (Type 1 and Type 2), we identified 15 journal papers directly related to diabetes education in Austria. Amongst these, the two most cited papers internationally are Pieber et al. (1995a) and Pieber et al. (1995b). These papers provided us with an initial set of contact details of the leading figures in patient-centred health in Austria. The scientometric study indicated the important formative role played by a group of practitioners working together at the Clinic Hospital in Graz, Styria in the mid-1990s. These contacts provided us with information on the key events and challenges, and how these challenges evolved over the period prior to the start of our research (i.e. pre-2007). One of the leading figures at Graz Clinic Hospital served as our primary informant. Through recommendation and desktop research we identified further interview candidates. With this community, we conducted semi-structured interviews, at multiple time points, over a seven year period. This included interviews with five leading actors in the Austrian patient-centred diabetes community who have played prominent roles in the national diffusion of diabetes education, and who were also involved in the founding and running of the Association of Diabetes Specialists, the Association of Diabetes Advisers, and other key professional organizations supporting the TPE in Austria over the past 20 years. The advantage of longitudinal interviews with these professionals over the past seven years is that it provides insight into the key challenges that presented themselves over that time period.

Using a "snowball technique" (Lincoln and Guba 1985), this initial group of interviews led to the identification of further members within the Austrian community of specialist practitioners. This additional set of interviewees includes senior practitioners from medical fields directly connected to diabetes care in hospitals, and senior representatives from two powerful organizations that play a key role in the funding of education programmes and the training of doctors in evidence-based medicine (EBM): the Social Health Insurance Fund and the Physicians' Chamber. The Social Health Insurance Fund is the body that funds diabetes education programmes for Type 2 patients in Austria. The Physicians' Chamber is responsible for further vocational training in diabetes monitoring and sequelae. The Physicians Chamber is important to the diffusion of the (Düsseldorf) TPE model in Austria. Only through training certified by the Physicians Chamber can physicians receive a certificate that entitles them to receive remuneration for Type 2 diabetes education. The Physicians' Chamber is a powerful organization in Austria representing the interests of all qualified physicians. All qualified physicians are obligatory members of this organization. Some of the early supporters for establishing the (Düsseldorf) TPE model also held functions in the regional branches of the 
Physicians' Chamber. In addition, interviews were carried out with a senior hospital cardiology consultant in a rural hospital in order to obtain an 'outsider' perspective. The rural hospital also offers diabetes education, but not according to the standards of the Dusseldorf model. Like diabetologists, cardiologists receive a basic training as internal physicians but subsequently specialise in a different field. This provides us with an external perspective but one that is much closer in terms of education than other types of physicians. These different participants were important for cross-checking information and also to gain a multi-perspective analysis of how the challenges facing patient-centred advocates have been negotiated.

Interviews followed a common thematic guide related to key events and challenges in the development, diffusion and embedding of Type 1 and Type 2 TPE in hospitals, the organization of in-patient and out-patient services in hospitals, the role of external stakeholders in affecting change, the role of professional networks, and education/training of practitioners. Interviews ranged in length from 60 and 120 minutes, with an average duration of around 70 minutes. The interviews were carried out in private offices or meetings rooms and all were digitally audiorecorded with the consent of participants. All recorded interviews were transcribed verbatim for the purpose of data analysis. Participants' interview narratives provided information about the identity of relevant actors, how this community was organized, how funding was secured from social health insurance funders, the organization of specialist training courses for qualified diabetologists and nurses in patient-centred diabetes care, how basic training of medical students in Austria was changed and the development of workshops and conferences for the dissemination of the latest research findings.

Table 1 provides a detailed inventory of all data sources, as well as the audience and source for whom that information was created.

TABLE 1 HERE

\subsection{Data Analysis}

Our interpretative qualitative data analysis was informed by and developed from the principles of grounded theory, but the intention was to elaborate and deepen existing theoretical debates through novel empirical findings (Strauss and Corbin 1998). This involved an iterative process of coding, categorisation and constant comparison, but where emergent codes were crossreferenced with existing concepts and theory. The initial stage involved close reading and open coding of data by authors $\mathrm{A}$ and $\mathrm{B}$, with the aim of identifying and discussing first order codes. The initial set of codes and emerging themes were discussed with author $\mathrm{C}$ to provide a level of independent reflection, and to discuss and clarify discrepant views.

Using the software package NVivo, systematic coding of data then proceeded, which involved first order coding (tagging) of data, together with contemporaneous interpretation and annotation of data extracts. Wherever possible, we used terms and language adequate at the 
level of meaning of the informants (van Maanen 1979). Through regular (fortnightly) review meetings, these codes were analysed for their internal consistency, coherence and interrelationships. This led to the identification of second order codes, where codes aligned or grouped, and subsequent third order categories.

The second step involved 'axial coding' (Strauss and Corbin 1998). Here we searched for relationships between categories, and assembled them into higher-order themes. Using NVivo we were able to identify representative examples into fewer categories and themes or, where necessary, parse collections of examples into more fine-grained categories. This process helped us gain an understanding of the relationships amongst categories and their related themes as interview data was collected. To mitigate against problems associated with retrospective accounts, statements regarding a finding are only made if it is corroborated by multiple informants. Representative quotes, therefore, represent corroborated findings.

\section{CASE STUDY OF PROFESSIONAL ASSOCIATIONS IN SOCIAL INNOVATION AND INSTITUTIONAL CHANGE}

\subsection{Background}

The Düsseldorf model of TPE follows a two-step approach. The first step involves the training of educators (i.e. internal physicians or family doctors) by physicians specialised in diabetes and endocrinology. The second step involves trained physicians working with diabetes patients, originally within a five-day inpatient course. This approach is based on Assal's model of TPE (Assal et al. 1985). The goal is for patients to be capable to self-manage their disease with minor support from their diabetes team. TPE provides the basic skills and knowledge for this selfmanagement.

Initially, a few diabetology departments in Austria began to deliver the Düsseldorf TPE model within their local hospitals. Early take-up occurred where the heads of clinic departments had an interest in TPE. It is notable that these lead adopters were mostly located within research hospitals. Consoli and Mina (2009) have previously highlighted the connecting role played by research hospital in the development and testing of new pharmaceutical drugs and new medical devices. This case study shows that academic medical centres and university hospitals can also be key sites of the adoption of new practices in chronic health management. However, there was much testing, demonstration, and organizational work done to done to ensure that TPE was to spread and become everyday practice across Austria.

Implementing TPE in the Austrian healthcare system required the enrolment of two key organizations, who are important for governing and funding health care services, education programmes and training doctors: the Social Health Insurance Fund and the Austrian Physicians' Chamber. The Physicians' Chamber represents the professional, social and economic interests of all registered physicians in Austria. The most important legal tasks of the Physicians' Chamber are, firstly, granting the right for employment (and self-employment) as 
a medical professional and, secondly, legal oversight of the general medical examination that is required to practice as a medical professional (ÖÄK 2016).

The Social Health Insurance Fund is the public healthcare provider within the Austrian healthcare system. In Austria, the provision of healthcare, financing and governance of healthcare is mainly a public function. The Austrian Social Healthcare Insurance Fund fulfils a crucial role in terms of financing. For TPE education services to be funded nationally, these must be on the services list of the Social Healthcare Insurance Fund. A second major role of Insurance Fund is the provision and governance of the Austrian healthcare system. This is a mandatory insurance, which entails that healthcare is delivered in case of need to those insured within the social health insurance system according to a catalogue of benefits. The inclusion of healthcare services in the catalogue of benefits is a crucial point. The catalogue of benefits is provided by physicians in independent practices and in hospitals, financed by the social healthcare insurance funds, and is subject to annual negotiation between the Physicians' Chamber (at the Länder level) and the Federation of Austrian Insurance Institutions (Hofmarcher and Quentin 2013; Hofmarcher and Rack 2006). Given continuous constraints placed on the budgets of the Social Healthcare Insurance Funds, these annual negotiations are inherently difficult.

For TPE to be implemented across Austria, the Social Healthcare Insurance and the Physicians' Chamber needed to be convinced that (1) this new education approach can be delivered to patients, and (2) that the new education programme would have an improved health benefit over the traditional compliance model.

These activities were taken up and organized by several professional diabetes associations who promote diabetes TPE in Austria. Of particular note is the institutional work that has been conducted by two professional associations: the Association of Diabetes Specialists, and the Association of Diabetes Educators. Both associations were originally set up to implement the St. Vincent Declaration and, as part of this, both associations have become advocates of TPE. The Association of Diabetes Specialists (ADS), founded in 1996, is a non-profit association that aims to improve the care and treatment of diabetes patients, and people with diabetes complications. Its members include doctors, nurses, counsellors and other professionals involved in the care of patients with diabetes. The ADS has around 400 members across Austria. The Association of Diabetes Educators (ADE) was founded in 1997, and followed a preexisting German association with aspects drawn from other countries, such as Denmark). The aim of the ADE is to assist in delivering diabetes TPE by changing the vocational training of nurses.

A number of third sector organizations within Austria also play an important role. Of particular note are the Austrian Diabetics Association and the Juvenile Diabetes Foundation (JDRF Europe), which act as lobby groups for diabetes TPE in Austria.

Finally, the case study shows that important supporting activities were undertaken by the European Association for Diabetes (EASD), an international professional association with links with the ADS and ADE. Founded in 1965, the EASD is the leading professional association for 
diabetes TPE in Europe with 8,000 plus members. It organizes a monthly scientific journal with a high impact factor. The EASD also holds a large Annual Meeting (EASD 2013).

In the next section of the paper we examine the institutional work that has been conducted by these professional associations and how these lay the ground for the establishment of the national Diabetes Management Programme (DMP) programme that finances the delivery of TPE for diabetes patients in six provinces in Austria.

\subsection{Creating a new institution: Identity construction, legitimacy and advocating.}

Here we consider the institutional work involved in creating identity and legitimacy for the new patient-centred institution in diabetology. Here we draw upon two sources. One is written data which has been collected (e.g. Sackett et al. 1996; WHO 1998; Porta et al. 2005). The other is face-to-face interviews with leading advocates of patient-centred diabetes health in Austria.

At the core of the patient-centred institution is the twinning of TPE and evidence-based medicine (EBM). Our empirical work shows, together, TPE and EBM together are considered to provide a radically new way of conducting diabetes medicine.

As well as being central to the identity of this community of practitioners, the combination of TPE and EBM are a source of legitimacy and much of the advocacy work for this new institution within diabetology. Advocacy is a form of institutional work associated with the creation of institutions because it offers marginalised actors the opportunity to create institutions by manipulating cognitive legitimacy (Elsbach and Sutton 1992; Suchman 1995).

EBM is the application of the scientific method to everyday medical practice. This changes the nature of work in diabetes care to one in which practice is combined with empirical testing through random control trials (RCTs). While RCTs are familiar in the development of pharmaceutical drugs, their application to other forms of medical practice is novel. The use of RCTs in medical practice gives rise to a moral claim where empirical evidence indicates that patients more effectively manage their own condition. It is asserted that, within the context of a new patient-practitioner relationship, there is democratisation of medical knowledge due to a change in social relations. As discussed in section 1, this is a key aspect of a social innovation.

"Evidence-based medicine threatens the established hierarchy. In the old days having knowledge gave authority. The Professor had access to all literatures, and so he had the greatest knowledge, and so authority. Evidence-based medicine is a process that challenges this old hierarchy because it democratises knowledge. First, it teaches everybody how to find out what is the clinical evidence. Second, it also teaches you to translate that knowledge into patient care... This is not always wanted and is resisted by [orthodox] doctors." (Interviewee ID \#1).

The scope of EBM is, of course, broader than the field of diabetology. It is the application of the scientific method to all aspects of clinical practice and therapy. The basic principle of EBM 
is that a practice or therapy should only be applied if there is empirical evidence that it has a proven beneficial effect for a specific condition (Sacket et al. 1996).

Within EBM, scientific independence and rigour is linked to dependence of research funding. We find rhetorical claims in our research data regarding the increased independence of EBM knowledge and its application to diabetes health. This is illustrated in the following statement from the Austrian Cochrane branch and the quote below.

"Centres, branches, and Cochrane Review Groups must seek its own financing, which may not come from commercial sources. Thus, the neutrality of the Cochrane Collaboration and the avoidance of conflicts of interest are guaranteed" (Austrian Cochrane branch http://www.cochrane.at accessed 4th March 2014).

Limitations arising from the funding of medicine (i.e. pharmacology and surgical interventions) by private business are widely recognised across medical fields, from practitioners dealing with chronic conditions to fields such as neurosurgery (Marsh 2014). Important to the ethos of EBM is independence from the pharmaceutical industry. The Cochrane Database of Systematic Reviews (CDSR) is a leading resource for systematic EBM reviews in health care, which must be funded independently of the pharmaceutical industry. Each 'Cochrane Review' is peerreviewed, prepared and supervised by a Cochrane Review Group (editorial team) in The Cochrane Collaboration. The Cochrane Review Group for Endocrinology and Metabolic Diseases includes TPE.

TPE acknowledges an important difference between chronic and acute conditions. In chronic conditions such as diabetes, where there is no drug or surgical cure, day-to-day management of the condition is overwhelmingly in the hands of the patient, who must make long-term healthy lifestyle changes involving diet, exercise, and medication. TPE involves educational activities that are essential to the management of pathological conditions, designed to help a patient (or a group of patients and their families) to manage their treatment and prevent avoidable complications, while keeping or improving their quality of life. TPE produces a therapeutic effect that is additional to that produced by pharmacological therapy, physical therapy and all other interventions (WHO 1998, p.75).

TPE in diabetology is part of a wider movement that advocates an 'empowered patient' model for chronic healthcare (Claridge and Fabian 2005). As noted above, this directly challenges the established practitioner-driven institution of medical professionalism. In the practitioner-driven institution, the physician determines the vast majority of service provision based on their institutionalised expertise and claims to professionalism. The patient-centred institution contains an alternative logic: that the patient is the most knowledgeable person about their condition and their daily life, and that it is the patient that should identify new ways of improving their health outcomes (Anderson and Funnell 2005).

TPE involves educational activities that are essential to the management of pathological conditions, designed to help a patient (or a group of patients and their families) to manage their treatment and prevent avoidable complications, while keeping or improving their quality of life. 
TPE produces a therapeutic effect that is additional to that produced by pharmacological therapy, physical therapy and all other interventions (WHO 1998, p.75).

A moral claim is made for TPE by patient-centred diabetologists; a claim that demarcates them from traditional practitioners. The first part of this moral claim is that pre-existing pharmacological and surgical interventions are ineffective and, hence, alternatives must be sought (Berger and Mühlhauser 1999; Porta et al. 2005). Interviewees also spoke of their frustrations with existing, traditional treatments and how they were led to search for an alternative during the 1980s.

"There was a clear need to do something. We could not continue with the old methods of treatment. But we did not know in the early days what else could be done, or how." (Interviewee ID \#2).

"Sectioning patients was not working. Blood glucose levels were brought under control when they were placed in hospital, for up to a week, but became uncontrolled when they went home. The problem was that the rigid regiment of diet and exercise was not sustainable in everyday life. It simply didn't fit." (Interviewee ID \#3)

The second part of the moral claim is that empirical evidence from random control trials (RCTs) indicates that patients more effectively manage their own condition. Given the Hippocratic Corpus of 'first, do no harm', maintaining the status quo is argued to be ethically and morally indefensible.

"The evidence is there. It already exists. I do not understand why they [traditonalists] do not change." (Interviewee ID \#3).

This quote reveals an expectation that clinical evidence showing the therapeutic effect of TPE should have been sufficient to engender radical change within diabetology in Austria. We also find this expectation expressed in journal publications of clinical trials, such as Mühlhauser et al. (1983), Mühlhauser et al. (1987), Jörgens et al. (1993), Plank et al. (2004), Starostina et al. (1994), Pieber et al. (1995b), Müller et al. (1999), and Müller et al. (2013). However, Nelson et al (2011) have observed that, while RCTs represent a 'gold standard' in the development of pharmaceutical drugs, these are only one part of a broader system of experimentation and learning that moulds the advance of medical know-how. Research by Greenhalgh et al. (2004) and Ferlie et al. (2005) goes further. They found that clinical trial data by itself, was not sufficient to ensure the implementation of new medical practices and treatments in hospitals.

\subsection{Role of professional associations in TPE development: Overtly political work, ensuring adherence to rule systems, and education.}

We now consider the institutional work conducted by the various national and international professional associations, and third sector organisations, discussed in section 4.1 Their work was essential to the development, delivery, and funding of diabetes TPE in Austria. Documentary material and face-to-face data highlight the importance of what Lawrence and Suddaby (2006) categorise as 'overtly political work', which was conducted with external 
funding agencies. This overtly political work, important for the creation of a new institution, included 'vesting' - creating rule structures that confer property rights; 'defining' - constructing a rule system that confers status and identity to the associations and membership of those associations; and 'advocating' - the mobilising political and regulatory support through direct and deliberate techniques of social persuasion.

The ADS works to implement structured documentation based on a standardised check-list, as postulated by the St. Vincent Declaration, quality feedback for healthcare providers (reports, analyses, open benchmarking), the organization of biannual meetings to encourage the development and diffusion of best practice to achieve the goals of the St. Vincent Declaration, and the promotion of quality circles as a method for professional education and open discussion on quality issues (Interviewees ID \#2 and \#4). Through these activities, the ADS has been heavily engaged in institutional 'defining' work - i.e. the constructing of a rule system that confers status and identity to the associations and membership of those associations that support TPE in Austria.

In addition to activities undertaken by the ADE and ADS, 'advocating' work was conducted by the Austrian Diabetics Association and the Juvenile Diabetes Foundation (JDRF Europe), who lobbied politicians and doctors for the right of patients to receive diabetes TPE (Interviewee ID \#3).

'Policing' is a third type of institutional work. As part of the ongoing maintenance work of an institution, it is important to ensure compliance through enforcement, auditing and monitoring work. In Austria, the Physicians' Chamber has governance and policing powers. It issues a certificate for those diabetologists (additional to the doctoral degree and the specialist training as diabetologists) who have undergone specific training activities under its auspices. This is to ensure quality in diabetes care. The ADS and ADE worked closely with the Physicians' Chamber when developing the Styrian Diabetes Training and Education Project and the national Disease Management Programme. This co-operation institutionalised within the Physicians' Chamber the supporting values, norms, and 'rules of the game' for patient-centred institution.

In addition to lobbying and policing activities, the case study shows the importance of 'educating' work. Prior to delivering TPE to patients one must first 'train the educators' in new ways of interacting with patients, new ways of delivering patients education, how to engage with patients regarding healthier lifestyles, and, thereby, more effectively self-manage their Type 2 diabetes (Halban and Jörgens 2002). In addition to the training courses organized by the Physicians' Chamber (see above), additional practitioner conferences were organized. Here medics discussed their experiences with TPE and disseminated information on particular medical care practices amongst fellow TPE supporters, and other who were interested to learn more about TPE.

The ADS and ADE organised and delivered an annual course for specialist diabetes nursing, and the ADS used its links with the EASD to deliver an Annual Postgraduate Course in Clinical Diabetology in Austria. Organised under the auspices of the EASD, the Course brought together 100 to 120 participants, who came from associations (such as the ADS and the ADE), hospitals 
and registered doctor practices, with lectures held on all aspects of patient-centred diabetes care. Local organisers also invited members of the Social Healthcare Insurance Fund to attend meetings, and members of the local organizing committee also held positions in the Physicians' Chamber. Important education work continues to be conducted by the ADE. It trains around 20 nurses per year. In September 2014, a university-level course for training specialist diabetes nurses commenced, and in the future it will be possible to earn ECTS points. ${ }^{1}$

As well as developing the training needed for diabetologists to effectively deliver TPE, the ADS, ADE, and some university hospitals were involved in informing and convincing ('educating') the Social Health Insurance Fund and the Physicians' Chamber in skills and knowledge necessary to support the new, patient-centred institution. Field notes of conversations with leading members of these associations (interviewees ID \#1 and \#3) and senior members of the Health Insurance Funds and the Physicians' Chamber (interviewees ID \#6 and \#7) reveal that this educating activity was particularly intensive between 1993 and 2000.

During this period, these associations received strong support from Michael Berger, the President of the EASD and a leading member of the IDF at that time. He was a leading international expert in TPE and had been involved in the first TPE trials in Düsseldorf. Berger gave lectures in Austria and accompanied Austrian TPE advocates in negotiations with the Social Healthcare Insurance Fund regarding the setting up of a national diabetes education programme. The support of leading international associations, such as the EASD and IDF, was important in the early years because it acted as a counterbalance to professional resistance from traditional compliance-oriented professionals, and the naturally slow mode of change in the Social Healthcare Insurance Fund.

Educating work was important for establishing trust between the organizations, and much of the focus was around the basic theoretical concepts of patient empowerment, the causes of patients' non-compliance, evidence-based medicine, and disease management (interviewees ID \#1, \#3, \#6, \#7). This educating work proved important for the eventual funding of the Styrian Diabetes Training and Education Project and the national Disease Management Programme Social Healthcare Insurance Funds.

To assist the discussion, a timeline of key events in presented in Table 2.

\section{TABLE 2 HERE}

As discussed above, the original version of diabetes TPE was developed in Düsseldorf during the early 1980s, and the earliest published evidence of its therapeutic effect were Mühlhauser et al. (1983), Assal et al. (1985), and Mühlhauser et al. (1987). These early findings attracted a few diabetologists working in Austria. However, this clinical trial evidence was not, by itself,

\footnotetext{
${ }^{1}$ European Credit Transfer and Accumulation System (ECTS) is a standard for comparing the study attainment and performance of higher education students across the European Union and other collaborating European countries.
} 
sufficient to persuade Austrian Social Healthcare Insurance Funds to finance the delivery of TPE in Austrian hospitals. Nor did the evidence attract large numbers of Austrian diabetologists to offer TPE in their departments. Responding to the demands of the Social Healthcare Insurance Fund to replicate the German research, diabetologists at the Medical University of Graz conducted clinical trials of TPE for Type 1 and Type 2 diabetes patients. Positive results were published in 1995 (Pieber et al. 1995a; Pieber et al. 1995b).

As noted in the previous section, those diabetologists involved in the first Austrian trials were disappointed that empirical evidence supporting the effectiveness of TPE did not engender radical change within the diabology community, or the financing of TPE in Austrian hospitals.

The first major project to offer TPE was the Styrian Diabetes Training and Education Project, which commenced in 2000. The aim of the Styrian project was to provide TPE to all patients diagnosed with Type 2 diabetes within all local hospitals. This required the formulation of a framework in which resource-efficient TPE that was remunerated by the (local) Styrian Social Healthcare Insurance Fund. The idea was to design and formulate (some of) the contractual relations between these key organizations.

The professional associations engaged in overtly political and coordination work, as the success of the Styrian project required a reframing of the roles of both the Styrian Social Healthcare Insurance Fund and the Styrian Physicians' Chamber.

In addition to being trained physicians (holding a university degree in medicine), those delivering TPE must be certified by the Styrian Physicians' Chamber as qualified trainers. Local physicians were trained by 'internists' who are specialised in diabetes and/or endocrinology. Those holding a certificate from the Styrian Physicians' Chamber are exclusively permitted to receive financial reimbursement from the Styrian Social Healthcare Insurance Fund.

The training programme for physicians is delivered over two days. They are trained in their new role of facilitator and the monitoring of the set of consequences and sequelae. In order to receive financial reimbursement, training physicians must also learn how to document a specific set of indicators on the patient's medical condition, and other impact of TPE on patients.

The certification of physicians was co-designed by members of the university hospitals, the ADS, and the Styrian Physicians' Chamber. The local Physicians' Chamber also promoted diabetes training programme amongst local physicians, who saw this as a means to improve the quality of patient care as well as generating additional income.

The associations also worked with the Styrian Social Healthcare Insurance Fund on its governance role for financial reimbursement. While TPE mostly took place at the residential doctors' practices or in hospitals, the Insurance Fund had to implement an auditing of TPE delivery; i.e. the date TPE was received by each patient, minimum number of patients signed up for each TPE session, the education material delivered, documentation sheets for physicians, and the formal requirements for reimbursement.

From the beginning of the Styrian project in 2000 until October 2009, 525 physicians were trained and, according to Styrian Social Healthcare Insurance Fund records around 9,600 
diabetes patients received TPE. A clinical study accompanying the project showed that, on average, all target parameters measuring diabetes control improved significantly after one year (Korsatko et al. 2007).

Based on the local Syrian project in Styria, work began in 2003 on the national Disease Management Programme (DMP) for diabetes education. The two professional associations, Graz University Clinic Hospital, and the Styrian Social Healthcare Insurance Fund worked on the development of TPE to be delivered in hospitals across Austria. The roll out of the DMP commenced in 2006.

\section{DISCUSSION AND CONCLUSIONS}

Patient-centred health is a radical social innovation. As the case study shows, it involves the democratisation of medicine through a new approach to managing chronic medical conditions; one that places the patient and his/her lifestyle and socio-economic conditions at the centre of the medical picture. As well as changing the means for delivering healthcare, this social innovation alters the pre-existing social relationship between medical practitioners and patients, making the patient the 'expert' and the medic the facilitator of healthcare.

The case study illustrates the slow pace of change in medicine, and the need for professional associations to actively work to make change occur. There exists a large body of clinical evidence, conducted in many countries, showing the therapeutic benefits of diabetes TPE programmes over traditional didactic education programmes (e.g. Assal et al. 1985; Starostina et al, 1994; Pieber et al. 1995a, Pieber et al. 1995b; Deakin et al. 2005; Deakin et al. 2006; Korsatko et al. 2007; Windrum et al. 2016a). Yet this body of evidence, by itself, was not sufficient to ensure the diffusion of patient-centred health in diabetes in Austria.

Greenhalgh et al. (2004) and Ferlie et al. (2005) have previously identified the importance of professional groups for the adoption of health innovations within a single department or hospital site. The case study provides us with a unique opportunity to examine this institutional work because, due to lack of support from the existing professional body, the Association of Diabetes Specialists and the Association of Diabetes Educators were established with the explicit task of conducting the institutional work needed to develop effective diabetes TPE and secure funding for its delivery in Austrian hospitals.

The case study reveals the range of institutional work which is needed in order to develop a social innovation in health, from a randomised clinical trial into a practical and efficient service that can be delivered in a hospital setting, and which meets the criteria for financial reimbursement by health insurance funds. These two professional associations developed and 'carried' the new patient-centred health institution, and conducted the key work of creation, maintenance and disruption needed for the social innovation to diffuse within the Austrian health system.

This research presented here complements previous studies by Jagd (2011), Slager et al. (2012), and Taupin (2013) that indicate the potential gains of exploring the creation of institutions from 
a work perspective. Jagd (2011) and Taupin (2013) have previously examined 'justification work' by actors who develop moral arguments to support their institutional projects and the complex debates that ensue. Slager et al.'s (2012), study of regulatory standards identified three types of institutional work - 'calculative framing, engaging, and valorizing' - which supported the design, legitimation, and monitoring processes needed for a standard to acquire regulatory power.

Institutional work involving identity construction is central to creating new institutions because identities describe the relationship between an actor and the field in which that actor operates. This form of institutional work has been found to be tied strongly to the development of professions (e.g. Brock et al. 1999; Covaleski et al. 199; Lounsbury 2001). Behaviour within organizations is regulated by the widely accepted beliefs, logics, schemas and values that are part of a larger institutional context (Meyer and Rowan, 1977; DiMaggio and Powell 1983; Scott 2008).

Our case study highlights how the connection between TPE and EBM provides a powerful base for legitimation because it twins ethos (TPE) with logos (EBM). The moral claim of TPE is that existing pharmacological practices are ineffective and that TPE, through educational activities, can produce a positive therapeutic effect. This moral claim is twinned with the logos of EBM, which is the application of the scientific method, for the first time, to everyday medical practice. Random control trials show better self-management in patients receiving TPE compared to patients receiving traditional, practitioner-driven education. The power of this new, abstract concept of patient-centred diabetology, combining TPE and EBM, is that it creates identity while simultaneously disrupting the moral foundations, and medical assumptions and beliefs of the pre-existing practitioner-driven institution.

In constructing an identity in which TPE and EBM are combined, patient-centred diabetologists are rhetorically laying claim to the scientific method within their everyday hospital practice. Advocating change in their medical field, TPE differentiates patient-centred diabetologists from traditional diabetologists, while EBM legitimises TPE by laying claim to the well-established principles from science. The rhetorical argument for TPE draws upon practices and theories of group learning that are well-established in the education field (WHO 1998). What is novel is the application of these methods to diabetes treatment. This requires specialist practitioners to be trained in, what is for them, new education methods.

The case study shows other types of institutional work conducted by the ADS, ADE and other national professional associations, linked to powerful international associations to conduct overtly political work, policing, and educating. Of particular interest is the way in which 'advocating' work was conducted. Professional associations worked very closely with the two key organizations who control funding in Austria, the Social Health Insurance Fund and the Physicians' Chamber, co-designing the TPE to be delivered in hospitals, practitioner certification, and the regulatory oversight procedures. This mobilisation of political and regulatory support was evident in first the Styrian Diabetes Training and Education Project and subsequently in the national Disease Management Programme. 
This co-operation institutionalises within the Social Health Insurance Fund and the Physicians' Chamber the supporting values, norms, and 'rules of the game' for patient-centred institution. Prior research on institutional work has discussed ways in which communities of practitioners police their members through incentives and sanctions. Here everyday policing work is undertaken by the Physicians Chamber, through certification. This is an interesting strategy. Traditional diabetologists must undertake formal training in the delivery of patient-centred education in order to be certified and, thereby, receive payments for delivering diabetes education.

The professional associations were actively engaged in two forms of educating work. One was the specifying of the training needed by diabetologists to effectively deliver TPE. The other was educating work with the Social Health Insurance Fund and the Physicians' Chamber. This was involved education regarding the existing evidence base in Germany and elsewhere on the clinical benefits of TPE, setting up meetings with leading foreign experts on TPE in order to educate them on the core concepts of patient empowerment, the causes of patients' noncompliance, evidence-based medicine, and disease management. This established trust amongst the organizations and was important for the development of core components of the Styrian Diabetes Training and Education Project and the national Disease Management Programme.

It is hoped that, as well as advancing understanding of social innovation and institutional change, this case study will stimulate further research on the creation of institutions from a work perspective. There is a need for future research to look beyond institutional entrepreneurs and to examine the institutional creation and disruption work which is undertaken by professional associations, not only in medicine but in other highly professionalised fields such as law, education, and accountancy. 


\section{References}

Anderson, R.M. and Funnell, M.M. 2005. Patient empowerment: reflections on the challenge of fostering the adoption of a new paradigm, Patient Education and Counseling, 57: $153-157$.

Assal, J.P., Mühlhauser, I., Pernet, A., Gfeller, R., Jörgens, V., and Berger, M. 1985. Patient education as the basis for diabetes care in clinical practice and research, Diabetologia, 28(8): 602-613.

BEPA. 2010. "Empowering people, driving change: Social innovation in the European Union."

Berger, M. and Mühlhauser, I. 1999. Diabetes care and patient oriented outcomes, Journal of the American Medical Association, 281: 1676-1679.

Brock, D.M., Powell, M.J. and Hinings, C.R. (Eds.). 1999. Restructuring the Professional Organization: Accounting, Healthcare and Law. London: Routledge.

Bundesministerium für Gesundheit. 2013. Österreichischer Diabetesbericht: Ausprägungen - Lösungsansätze - Herausforderunge. Vienna: Bundesministerium für Gesundheit.

Chiappero, E. and N. Von Jacobi. 2015. How can Sen's 'Capabilities Approach' contribute to understanding the role of social innovations for the marginalised? CRESSI Working Paper 3/2015. Available at http://www.sbs.ox.ac.uk/sites/default/files/researchprojects/CRESSI/docs/CRESSI_Working_Paper_3_D1.1_Chp3_18Nov2014.pdf. Last viewed 1.11.15.

Claridge, J.A. and Fabian T.C. 2005. History and development of evidence-based medicine, World Journal of Surgery, 29(5): 547-553.

Cobb-Clark, D.A., Kassenboehmer, S.C., Schurer, S. 2013. Healthy habits: The connection between diet, exercise, and locus of control, Journal of Economic Behavior and Organization, forthcoming.

Consoli, D. and A. Mina. 2009. "An evolutionary perspective on health innovation systems." Journal of Evolutionary Economics 19 (2):297-319. doi: DOI 10.1007/s00191-0080127-3.

Coriat, B. and Weinstein, O. 2002. Organizations, firms and institutions in the generation of innovation, Research Policy, 31: 273-290.

Covaleski, M.A., Dirsmith, M.W., Heian, J.B. and Samuel, S. 1998. The calculated and the avowed: Techniques of discipline and struggle over identity in Big Six public accounting firms, Administrative Science Quarterly, 43:293-327.

Currie, G., Lockett, A., Waring, J., Finn, R. and Martin, G. 2012. Institutional work to maintain professional power: re-creating the model of medical professionalism, Organization Studies, 33(7): 937-962.

Damschroder, L.J., Aron, D.C., Keith, R.E., Kirsh, S.R., Alexander, J.A., and Lowery, J.C. 2009. Fostering implementation of health services research findings into practice: a consolidated framework for advancing implementation science. Implementation Science, 4(1), 1 .

Deakin, T., McShane, C.E., Cade, J.E., and Williams, R.D. 2005. Group based training for self-management strategies in people with type 2 diabetes mellitus. Cochrane Database System Reviews, Apr 18; (2):CD003417.

Deakin, T.A., Cade, J.E., Williams, R., Greenwood, D.C., 2006. Structured patient education: the diabetes X-PERT Programme makes a difference. Diabetic Medicine, 23(9): 944-954.

DiMaggio, P.J. and Powell, W.W. 1983. The iron cage revisited: Institutional isomorphism and collective rationality in organizational fields, American Sociological Review, 48: 147-160. 
Duke, S.A., Colagiuri, S., and Colagiuri, R. 2009. Individual patient education for people with type 2 diabetes mellitus. Cochrane Database System Reviews, Jan 21; (1):CD005268.

EASD. 2013. European Association for the Study of Diabetes website (www.easd.org/) last accessed 28th November 2013.

Edquist, C. and Johnson, B. 1997. Institutions and organizations in systems of innovation. In: Edquist, C. (Ed.), Systems of Innovation - Technologies, Institutions and Organizations. London: Pinter Publishers/Cassel Academic. pp. 41-60.

Elsbach, K.D. and Sutton, R.I. 1992. Acquiring organizational legitimacy through illegitimate actions: A marriage of institutional and impression management theories, Academy of Management Journal, 35(4): 699-738.

Elster, J. 1989. Social norms and economic theory, Journal of Economic Perspectives, 3(4): 99-117.

Evetts, J. 2006. The sociology of professional groups: new directions, Current Sociology, 54 (1): 133-143.

Ferlie, E., Fitzgerald, L., Wood, M. and Hawkins, C. 2005. The Nonspread of innovations: The mediating role of professionals. Academy of Management Journal, 48 (1): 117-134.

Fligstein, N. and McAdam, D. 2012. A Theory of Fields. Oxford University Press.

Freidson, E. 1985. The reorganization of the medical profession. Medical Care Review, 42: 11-35.

Funnel, M.M. and Anderson, R.M. 2000. The problem with compliance in diabetes, Journal of the American Medical Association, 284 (13): 1709.

Gebietskrankenkasse, 2004. Innovationsprojekt Modell Disease Management. Existierende Versorgungsmodelle. Final report. Available at: http://www.bmg.gv.at/cms/home/attachments/5/7/7/CH1079/CMS1123242283163/bei lage_1_diabetesplan.pdf. Last viewed 10.04.14.

Goodrick, E. and Reay, T. 2011. Constellations of institutional logics: changes in the professional work of pharmacists. Work and Occupations, 38: 372-416.

Greenhalgh, T., Robert, G., Macfarlane, F., Bate, P., and Kyriakidou, O. 2004. Diffusion of innovations in service organizations: Systematic review and recommendations. Milbank Quarterly, 82(4): 581-629.

Greenwood, R., Suddaby, R., and Hinings, C.R. 2002. Theorizing change: The role of professional associations in the transformation of institutionalized fields. Academy of Management Journal, 45: 58-80.

Halban, P. and Jörgens, V. 2002. Michael Berger, in Memoriam. European Association for the Study of Diabetes. News Section 10/2002.

Hall, M. and Felton, A.M. 2009. The St Vincent declaration 20 years on - defeating diabetes in the 21st century, Diabetes Voice, 54(2): 42-44.

Hargrave, T.J. and van de Ven, A.H. 2009. Institutional work as the creative embrace of contradiction. In: T.B. Lawrence, R. Suddaby, and B. Leca (eds.), Institutional Work: Actors and Agency in Institutional Studies of Organizations. Cambridge: Cambridge University Press. pp. 120-140.

Hochgerner, J. 2013. "Social innovations and the advancement of the general concept of innovation". In: Ruíz Viñals, C. and Parra Rodríguez, C. (Eds), Social Innovation: New Forms of Organisation in Knowledge-Based Societies, London: Routledge, pp. 12-18.

Hofmarcher, M. and Quentin, W. 2013. Austria: Health system review. Health Systems in Transition, 1- 291.

Hofmarcher, M.M. and Rack, H-M. 2006. Austria: Health system review. Health Systems in Transition, 1-247.

Hood, C. 1991. A public management for all seasons?, Public Administration 69(1): 3-19.

Howaldt, J. and Jacobsen, H. (Eds.). 2010. Soziale Innovation. Auf dem Weg zu einem postindustriellen Innovationsparadigma. Wiesbaden: VS Verlag. 
IDF. 2009. International Diabetes Federation Diabetes Atlas 4th Edition. Brussels, Belgium: International Diabetes Federation.

IDF. 2011. International Diabetes Federation Diabetes Atlas 5th Edition. Brussels, Belgium: International Diabetes Federation.

Jagd, S. 2011. Pragmatic sociology and competing orders of worth in organizations. European Journal of Social Theory, 14: 343-359.

Jörgens, V. Grüßer, M., Bott, U., Mühlhauser, I., and Berger, M. 1993. Effective and safe translation of intensified insulin therapy to general internal medicine departments. Diabetologia, 36: 99-105.

Kitson, A.L., Rycroft-Malone, J., Harvey, G., McCormack, B., Seers, K., and Titchen, A. (2008). Evaluating the successful implementation of evidence into practice using the PARiHS framework: theoretical and practical challenges. Implementation Science, 3(1), 1.

Korsatko, S., Habacher, W., Rakovacs, I., Plank, J., Seereiner, S., Beck, P., Gfrerer, R., Mrak, P., Bauer, B., Großschädl, M., Pieber, T., 2007. Evaluation of a teaching and treatment program in over 4000 type 2 diabetic patients after introduction of reimbursement policy for physicians. Diabetes Care, 30(6): 1584-1586.

Kumar, N., Stern, L.W. and Anderson, J.C. 1993. Conducting interorganizational research using key informants. Academy of Management Journal, 36:1633-1651.

Lave, J. and Wenger, E. 1991. Situated Learning: Legitimate Peripheral Participation. Cambridge: Cambridge University Press.

Lawrence, T.B. and Suddaby, R. 2006, Institutions and institutional work. In: S. Clegg, C. Hardy, T.B. Lawrence and W.N. Nord (eds.), Handbook of Organization Studies (2nd Edition), London: Sage, pp. 215-254.

Lawrence, T.B., Suddaby, R. and Leca, B. 2009. 'Introduction: Theorizing and studying institutional work'. In: T.B. Lawrence, R. Suddaby, and B. Leca (eds.), Institutional Work: Actors and Agency in Institutional Studies of Organizations. Cambridge: Cambridge University Press. pp. 1-27.

Lawrence, T.B., Leca, B. and Zilber, T. 2013. Institutional work: Current research, new directions, and overlooked issues. Organization Studies, 34(8): 1023-1033.

Light, D. 1995. Countervailing powers: a framework for professions in transition. In T. Johnson, G. Larkin, and M. Saks (Eds.), Health Professions and The State in Europe. London: Routledge.

Lincoln, Y.S. and Guba, E.G. 1985. Naturalistic Inquiry, London: Sage.

Lounsbury, M. 2001. Institutional sources of practice variation: Staffing university and college recycling programs, Administrative Science Quarterly, 46: 29-56.

Maguire, S. and Hardy, C. 2009. Discourse and deinstitutionalization: The decline of DDT. Academy of Management Journal, 52(1): 148-178.

Marsh, H. 2014. Do No Harm: Stories of Life, Death and Brain Surgery, London: Weidenfeld \& Nicolson.

May, C. and Finch, T. 2009. Implementing, embedding, and integrating practices: an outline of normalization process theory. Sociology, 43(3), 535-554.

McClelland, C.E. 1990. 'Escape from freedom? Reflections on German professionalization 1870-1933'. In: Torstendahl R and Burrage M (eds), The Formation of Professions: Knowledge, State and Strategy, London: Sage, pp.97-113.

McKinlay, J. and Stoeckle, J. 1988. Corporatization and the social transformation of doctors. International Journal of Health Services, 18(2): 191-205.

Mendell, M. and Neamtan, N. (2010), "The social economy in Quebec: towards a new political economy", in Mook, L., Quarter, J. and Ryan, S. (Eds), Researching the Social Economy, University of Toronto Press, Toronto, pp. 63-83.

Meyer, J.W. and Rowan, B. 1977. Institutionalized organizations: Formal structure as myth and ceremony, American Journal of Sociology, 83(2): 340-363. 
Mühlhauser, I., Jörgens, V., Berger, M., Graninger, W., Gürtler, W., Hornke, L., Kunz, A., Schernthaner, G., Scholz, V. and Voss. H.E. 1983. Bicentric evaluation of a teaching and treatment programme for type 1 (insulin-dependent) diabetic patients: Improvement of metabolic control and other measures of diabetes care for up to 22 months, Diabetologia, 25: 470-476.

Mühlhauser, I., Bruckner, I., Berger, M., Cheta, D., Jörgens, V., Ionescu-Tîrgovişte, C., Scholz, V. and Mincu, I. 1987. Evaluation of an intensified insulin treatment and teaching programme as routine management of Type 1 (insulin-dependent) diabetes. The BucharestDüsseldorf Study, Diabetologia, 30: 681-690.

Müller, N., Kloos, C., Sämann, A., Wolf, G., and Müller U.A. 2013. Evaluation of a treatment and teaching refresher programme for the optimization of intensified insulin therapy in type 1 diabetes. Patient Education and Counselling, 93(1):108-113.

Müller, U.A., Femerling, M., Reinauer, K.M., Risse, A., Voss, M., Jörgens, V., Berger, M., and Mühlhauser, I. 1999. Intensive treatment and education of NIDDM as clinical routine. A nationwide quality-circle experience in Germany, Diabetes Care, 22 (2):1329-1334.

Murray, E., Treweek, S., Pope, C., MacFarlane, A., Ballini, L., Dowrick, C., and Ong, B. N. 2010. Normalisation process theory: a framework for developing, evaluating and implementing complex interventions. BMC medicine, 8(1), 1.

Nelson, R.R., Buterbaugh, K., Perlb, M. and Gelijns, A. 2011. How medical know-how progresses, Research Policy, 40: 1339- 1344.

North, D. 1990. Institutions, Institutional Change and Economic Performance. Cambridge UK: Cambridge University Press.

ÖÄK. 2016. Aufgaben der ÖÄK: Mission Statement. http://www.aerztekammer.at/aufgaben-der-oesterreichischen-aerztekammer. Last viewed: 23.12.2016.

ÖDG. 2009. Leitlinien Diabetes Mellitus - Anleitungen für die Praxis. Österreichischen Diabetes Gesellschaft, Wien Klin Wochenschr 121/21-22 [Suppl 5]: 1-87 Vienna: SpringerVerlag.

ÖDG. 2012. Leitlinien Diabetes Mellitus - Anleitungen für die Praxis. Österreichischen Diabetes Gesellschaft, Wien Klin Wochenschr 124 [Suppl 2]: 1-128. Vienna: Springer-Verlag. Oliver, C. 1992. The antecedents of deinstitutionalization, Organization Studies, 13: 563588.

Phills, J. A. J., K. Deiglmeier, and D.T. Miller. 2008. "Rediscovering Social Innovation." Social Innovation Review (Stanford: Stanford Graduate School of Business, Fall).

Pieber, T.R., Holler, A., Siebenhofer, A., Brunner, G.A., Semlitsch, B., Schattenberg, S., Zapotoczky, H., Rainer, W., and Krejs, G.J. 1995a. Evaluation of a structured teaching and treatment programme for type 2 diabetes in general practice in a rural area of Austria. Diabetic Medicine, 12(4): 349-354.

Pieber, T.R., Brunner, G.A., Schnedl, W.J., Schattenberg, S., Kaufmann, P. and Krejs, G.J. 1995b. Evaluation of a structured outpatient group education program for intensive insulin therapy, Diabetes Care, 18: 625-630.

Plank, J., Köhler, G., Rakovac, I., Semlitsch, B.M., Horvath, K., Bock, G., Kraly, B., and Pieber, T.R. 2004. Long-term evaluation of a structured outpatient education programme for intensified insulin therapy in patients with type 1 diabetes: a 12 year follow-up, Diabetologia, 47: 1370-1375.

Pol, E. and Ville, S. 2009. "Social innovation: Buzz word or enduring term?" Journal of Socio-Economics, 38(6), pp. 878-885.

Porta, M., Miselli, V., Trento, M., and Jörgens, V. (eds). 2005. Embedding Education into Diabetes Practice, Front Diabetes, Karger: Basel. 
Reinstaller, A. 2014. An evolutionary view on social innovation, and the process of economic change, Mimeo, 2 February 2014. Earlier version available at: http://www.foreurope.eu/fileadmin/documents/pdf/Workingpapers/WWWforEurope_WPS_n o043_MS51.pdf.

Richez-Battesti, N. and Vallade, D. 2009. ESS et innovations sociales : Quel modèle socio économique d'incubateur?" Revue d'innovation, 30(2): 41-61.

Ruede, D. and Lurtz, K. 2012. Mapping the various meanings of social innovation: Towards a differentiated understanding of an emerging concept, EBS Business School Research Paper Series, (12-03). Available at: https://www.ebs.edu/fileadmin/redakteur/funkt.dept.sol/CC_SISE/Rueede, \%20Lurtz\%20\%20mapping\%20the\%20various\%20meanings\%20of\%20social\%20innovation.pdf. Last viewed: 28.5.2015.

Ruíz Viñals, C. 2013. "Introduction to social innovation as a new form of organization in knowledge-based societies. In: Ruíz Viñals, C., and Parra Rodríguez, C. (Eds.), Social Innovation: New Forms of Organisation in Knowledge-Based Societies, London: Routledge, pp. 3-11.

Taupin, B. 2013. The more things change... Institutional maintenance as justification work in the credit rating industry. $M @ n @ g e m e n t, 15: 529-562$.

Sackett, D.L., Rosenberg, W.M., Gray, J.A., Haynes, R.B., and Richardson, W.S. 1996. Evidence based medicine: What it is and what it isn't. British Medical Journal, 312(7023): 7172.

Science Communication Unit (2014). Science for Environment Policy In-depth Report: Social Innovation and the Environment. Science Communication Unit, University of the West of England, Bristol. UK. Available at: http://ec.europa.eu/environment/integration/research/newsalert/pdf/IR10_en.pdf. Last viewed: 1.11.15.

Scott, W.R. 2008. Institutions and Organizations, (3rd edition). Thousand Oaks, CA: Sage.

Scott, W.R., Ruef, M., Mendel, P.J. and Caronna, C.A. 2000. Institutional Change and Healthcare Organizations: From Professional Dominance to Managed Care. Chicago, IL: University of Chicago Press.

Slager, R., Gond, J-P., and Moon, J. 2012. Standardization as institutional work: The regulatory power of a responsible investment standard. Organization Studies, 33: 763-790.

Starostina, E., Antsiverov, M., Galsytan, G., Trautner, C., Jörgens, V., Bott, U., Mühlhauser, M., and Berger, M. 1994. Effectiveness and cost-benefit analysis of intensive treatment and teaching programmes for type-1-(insulin-dependent) diabetes mellitus in Moscow -blood glucose versus urine glucose monitoring. Diabetologia, 37:170-176.

Strauss, A. and Corbin, J. 1998. Techniques and Procedures for Developing Grounded Theory ( $2^{\text {nd }}$ edition). London: Sage.

Suchman, M.C. 1995. Managing legitimacy: Strategic and institutional approaches. Academy of Management Review, 20 (3): 571-610.

van Maanen, J. 1979. Reclaiming qualitative methods for organizational research: A preface. Administrative Science Quarterly, 24(4): 520-526.

VÖD. 2006. Qualitatätsstandards für österreichische Patient/inn/enschulungsprogramme im Rahmen des DMP - Diabetes "Therapie aktiv - Diabetes im Griff"

Waring, J. and Bishop, S. 2013. McDonaldization or commerical re-stratification: corporatization and the multimodal organisation of English doctors, Social Science and Medicine, 82: 147-55.

Waring, J. and Currie, G. 2009. Managing expert knowledge: organizational challenges and managerial futures for the UK medical profession. Organization Studies, 30(7): 755-778.

Weick, K. E. 1995. Sensemaking in Organizations. Thousand Oaks, CA: Sage. 
WHO. 1998. Therapeutic Patient Education. WHO Regional Office for Europe: Copenhagen.

http://www.euro.who.int/_data/assets/pdf_file/0007/145294/E63674.pdf last accessed 5th March 2014.

Windrum. P., García-Goñi, M., and Coad, H. 2016a. The impact of patient-centred versus didactic education programmes in chronic patients by severity. The case of type 2 diabetes mellitus, Value in Health. 19 (4): 353-362.

Windrum. P., Schartinger, D., Rubalcaba, L., Gallouj, F., and Toivonen, M. 2016b. The co-creation of multi-agent social innovations: A bridge between service and social innovation research, European Journal of Innovation Management, 19(2): 150- 166. 
Table 1. Data Inventory

\begin{tabular}{|c|c|c|c|}
\hline Data type & Quantity & Purpose for this study & Intended audience \\
\hline $\begin{array}{l}\text { Strategic } \\
\text { reports }\end{array}$ & 1860 pages in 16 reports & $\begin{array}{l}\text { Information on diabetes in } \\
\text { Austria, strategic reports on } \\
\text { implemented programmes } \\
\text { diabetes training for medical } \\
\text { practitioners }\end{array}$ & Policy makers \\
\hline $\begin{array}{l}\text { Papers in } \\
\text { scholarly } \\
\text { journals }\end{array}$ & 110 pages in 15 journal papers & $\begin{array}{l}\text { Papers directly related to } \\
\text { diabetes education in Austria }\end{array}$ & $\begin{array}{l}\text { Academics, policy } \\
\text { makers }\end{array}$ \\
\hline Web sources & 90 pages collected from 20 URLs & $\begin{array}{l}\text { Information on organisations } \\
\text { and their history }\end{array}$ & $\begin{array}{l}\text { Web representation } \\
\text { of organisations for } \\
\text { interested public }\end{array}$ \\
\hline $\begin{array}{l}\text { Statistical } \\
\text { data }\end{array}$ & - & $\begin{array}{l}\text { Data on diabetes and health } \\
\text { care in Austria }\end{array}$ & $\begin{array}{l}\text { General public, } \\
\text { policy makers, } \\
\text { academics }\end{array}$ \\
\hline $\begin{array}{l}\text { Non- } \\
\text { participatory } \\
\text { Observation }\end{array}$ & $\begin{array}{l}20 \text { hours observation of patient- } \\
\text { centred education, } 10 \text { hours } \\
\text { observation of traditional (didactic) } \\
\text { education }\end{array}$ & $\begin{array}{l}\text { Observation on content and } \\
\text { delivery of patient-centred } \\
\text { and traditional education } \\
\text { programmes }\end{array}$ & $\begin{array}{l}\text { Analysis for } \\
\text { research study }\end{array}$ \\
\hline \multirow[t]{9}{*}{ Interviews } & 8 interviewees & Strategic actors, informants & $\begin{array}{l}\text { Analysis for } \\
\text { research study }\end{array}$ \\
\hline & \#1 Senior diabetology consultant & & \\
\hline & Senior diabetology consultant & & \\
\hline & Senior diabetology consultant & & \\
\hline & Senior diabetes nurse & & \\
\hline & \#5 Senior diabetology consultant & & \\
\hline & $\begin{array}{lll}\text { \#6 } & \text { Senior Manager Social } \\
& \text { Insurance Fund }\end{array}$ & & \\
\hline & $\begin{array}{l}\text { \#7 } \begin{array}{l}\text { Senior Member of Physicians } \\
\text { Chamber }\end{array}\end{array}$ & & \\
\hline & \#8 Senior cardiology consultant & & \\
\hline
\end{tabular}


Table 2. Timeline of Events

\begin{tabular}{|c|c|c|}
\hline Event & Year & Data sources \\
\hline \multicolumn{3}{|l|}{ Influential events outside Austria } \\
\hline $\begin{array}{l}\text { Development of the 'Düsseldorf model' by research } \\
\text { teams in Germany and Switzerland. RCT evidence } \\
\text { published. }\end{array}$ & $1980-1984$ & $\begin{array}{l}\text { Porta et al. (2005); WHO (1998) } \\
\text { Mühlhauser et al. (1983); } \\
\text { Mühlhauser et al. (1987); WHO } \\
\text { (1998); Porta et al. (2005). }\end{array}$ \\
\hline St Vincent Declaration & 1989 & $\begin{array}{l}\text { Archive records; Hall and Felton } \\
\text { (2009). }\end{array}$ \\
\hline $\begin{array}{l}\text { Evidence Based Medicine (EBM) is developed. } \\
\text { Cochrane Review Group for Endocrinology and } \\
\text { Metabolic Diseases set up. }\end{array}$ & $1990-1994$ & Sackett et al. (1996) \\
\hline \multicolumn{3}{|l|}{ Influential events in Austria } \\
\hline $\begin{array}{l}\text { First national course to deliver training in diabetes } \\
\text { nursing. }\end{array}$ & 1985 & Interviewees ID \#4, ID \#5 \\
\hline $\begin{array}{l}\text { First clinical studies in Austria providing evidence on } \\
\text { effectiveness of diabetes training using the Düsseldorf } \\
\text { model. Studies are conducted at the Graz University } \\
\text { Clinic Hospital in Styria. }\end{array}$ & 1995 & $\begin{array}{l}\text { Pieber et al. (1995a), Pieber et al } \\
\text { (1995b). }\end{array}$ \\
\hline $\begin{array}{l}\text { Foundation of Austrian Association of Diabetes } \\
\text { Specialists (ADS). }\end{array}$ & 1996 & Archival records, ADS website \\
\hline $\begin{array}{l}\text { The first Annual Postgraduate Course in Clinical } \\
\text { Diabetology, under the auspices of the EASD- } \\
\text { Postgraduate Education Subcommittee. Attended by 100- } \\
120 \text { participants. }\end{array}$ & 1996 & $\begin{array}{l}\text { Archival records, Folder of } 11^{\text {th }} \\
\text { Postgraduate course on clinical } \\
\text { diabteology, } 2007\end{array}$ \\
\hline $\begin{array}{l}\text { Foundation of Association of Diabetes Educators (ADE). } \\
\text { This Association organises and delivers annual course to } \\
\text { become specialist diabetes nurse. } \\
\text { Prior to the Association of Diabetes Educators, there had } \\
\text { been a working group for diabetes educators for several } \\
\text { years. }\end{array}$ & 1997 & $\begin{array}{l}\text { Archival records of the ADE, e- } \\
\text { mail correspondence. }\end{array}$ \\
\hline $\begin{array}{l}\text { Styrian Diabetes Training and Education Project. } \\
\text { Training and education programme for Type } 2 \text { diabetes } \\
\text { patients. The official organisers are the Styrian Social } \\
\text { Healthcare Insurance Fund and the Styrian Physicians' } \\
\text { Chamber. }\end{array}$ & 2000 & Gebietskrankenkasse (2004). \\
\hline $\begin{array}{l}\text { Disease Management Programme (DMP) for diabetes } \\
\text { education is developed. Contract between Graz } \\
\text { University Clinic Hospital and Styrian Social Healthcare } \\
\text { Insurance Fund to design the disease management } \\
\text { programme for hospitals across Austria. }\end{array}$ & 2003 & $\begin{array}{l}\text { Bundesministerium für } \\
\text { Gesundheit (2013) }\end{array}$ \\
\hline $\begin{array}{l}\text { The Association of Diabetes Educators issues quality } \\
\text { standards in diabetes education in Austria. } \\
\text { But these are not obligatory in the delivery of the } D M P \text {. }\end{array}$ & 2006 & VÖD (2006) \\
\hline
\end{tabular}




\begin{tabular}{|l|c|c|}
\hline $\begin{array}{l}\text { First implementation of the DMP. Cooperation by } \\
\text { Physicians' Chamber and Social Healthcare Insurance } \\
\text { Funds at national level, and in participating provinces. }\end{array}$ & 2007 & $\begin{array}{c}\text { Bundesministerium für } \\
\text { Gesundheit (2013) }\end{array}$ \\
\hline $\begin{array}{l}\text { New version of ÖDG Guidelines. First time that this } \\
\text { includes a chapter dedicated to diabetes education. }\end{array}$ & 2009 & ÖDG (2009) \\
\hline $\begin{array}{l}\text { Last annual Postgraduate Course in Clinical Diabetology } \\
\text { held. }\end{array}$ & 2007 & Interviewees ID \#3, ID \#5. \\
\hline Current set of ÖDG Guidelines issued. & 2012 & ÖDG (2012) \\
\hline $\begin{array}{l}\text { Funding ends for the Association of Diabetes Specialists } \\
\text { (FQSD-Ö). }\end{array}$ & 2013 & 2014 \\
\hline $\begin{array}{l}\text { Annual course to train nurses to become specialist } \\
\text { diabetes nurses commences September 2014. This is a } \\
\text { university-level course. }\end{array}$ & & Interviewees ID \#1, ID \#5 \\
\hline
\end{tabular}

